\title{
Isolation and biological activity of triglycerides of the fermented mushroom of Coprinus comatus
}

\author{
Jun Ren ${ }^{1}$, Jin-Li Shi ${ }^{2}$, Chun-Chao Han ${ }^{3}$, Zhen-Quan Liư ${ }^{4}$ and Jian-You Guo ${ }^{1,5^{*}}$
}

\begin{abstract}
Background: Although many physiological functions of Coprinus comatus have been reported, there has been no report on the antinociceptive activity of Coprinus comatus. Therefore, the objective of the present study is to demonstrate the production, isolation, and biological properties of triglycerides (TFC) of the fermented mushroom of Coprinus comatus.

Methods: The effects of TFC on cytokines levels, total antioxidant activity, antinociceptive effects in vivo, $\mathrm{LD}_{50}$ and tactile hyperalgesia were analyzed respectively.

Results: TFC treatment decreased the levels of cytokines and total antioxidant status (TAOS) and inhibited the acetic acid-induced abdominal constrictions in mice. In addition, TFC reduced CFA-induced tactile hyperalgesia in a dose-dependent manner and the LD 50 of TFC was determined to be $400 \mathrm{mg} / \mathrm{kg}$. However, TFC did not significantly inhibit the reaction time to thermal stimuli in the hot-plate test.

Conclusions: TFC showed anti-inflammatory, antioxidant, peripheral antinociceptive and antihyperalgesic activity in various models of inflammatory pain. The data suggest that TFC may be a viable treatment option for inflammatory pain.
\end{abstract}

\section{Background}

Edible fungi have a long history of use in Traditional Chinese Medicine [1]. Coprinus comatus is a basidiomycete fungus claimed to benefit glycaemic control in diabetes. Many physiological functions of Coprinus comatus have been reported, such as anti-cancer properties [2], immunomodulatory [3] and hypoglycemic activity [4]. Stadler et al. reported that agaricoglycerides, a new class of fungal secondary metabolites isolated from several basidiomycetes, showed strong activities against neurolysin, a protease involved in the regulation of dynorphin and neurotensin metabolism, and even exhibited moderate analgesic in vivo [5]. The agaricoglycerides are a new class of fungal secondary metabolites that constitute esters of chlorinated 4-hydroxy benzoic acid and glycerol. Although the crude extract from Coprinus comatus was no beneficial effect at lower doses in mice subjected to acetic-acid writhing test, formalin test and

\footnotetext{
* Correspondence: guojianyou@126.com

'Department of Psychology, Zhejiang Normal University, Jinhua 321004, P. R. China

${ }^{5}$ Key Laboratory of Mental Health, Institute of Psychology, Chinese Academy of Sciences, Beijing 100101, P. R. China

Full list of author information is available at the end of the article
}

hot-plate test [6], there has been no report on the antinociceptive activity of agaricoglycerides extract from Coprinus comatus. Therefore, the objectives of the present study were to demonstrate the production, isolation, and biological properties of triglycerides of the fermented mushroom of Coprinus comatus.

\section{Methods}

Fermented mushroom of coprinus comatus

The seed of Coprinus comatus was purchased from the Agricultural Culture Collection of China.

First, the seed was grown at $28^{\circ} \mathrm{C}$ for 5 days on PDA slants $(1,000 \mathrm{~mL} 20 \%$ potato extract liquid $+20.0 \mathrm{~g}$ dextrose $+20.0 \mathrm{~g}$ agar) and then maintained at $4^{\circ} \mathrm{C}$ in a refrigerator. Five to six pieces of the mycelia of Coprinus comatus were transferred from a slant into $250 \mathrm{~mL}$ Erlenmeyer flasks containing $100 \mathrm{~mL}$ liquid medium $(20 \%$ potato extract liquid $+2.0 \%$ dextrose $+0.1 \% \mathrm{KH}_{2} \mathrm{PO}_{4}+$ $0.05 \% \mathrm{MgSO}_{2}$ ). The culture was incubated at $27^{\circ} \mathrm{C}$ on a rotary shaker at $180 \mathrm{rpm}$ for 5 days.

A 120-h-old liquid culture was homogenized using a sterilized blender and then inoculated to $500 \mathrm{~mL}$ Erlenmeyer flasks containing $300 \mathrm{~mL}$ of fermented culture

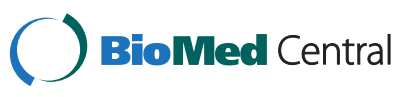


medium. The volume of inoculum was $15 \mathrm{~mL}$, which was then cultivated under the same condition. The 168-h-old culture medium was used for extraction [7-9].

\section{Triglycerides extracted from fermented mushroom of coprinus comatus (TFC)}

The methodology for extraction of triglycerides was described in detail by Han et al. [10]. Briefly, mycelia were separated from the culture fluid by filtration and extracted twice with acetone in an ultrasonic bath. The extract was filtered, and the acetone was removed in vасио to yield an aqueous residue. This residue was diluted with tap water and subsequently extracted three times with EtOAc. The combined organic phases were dried over $\mathrm{Na}_{2} \mathrm{SO}_{4}$ and evaporated in vacuo to yield an oily residue.

\section{Acute toxicity study}

When there is no information of TFC on toxicity, it is recommended to use the starting dose of $250 \mathrm{mg} / \mathrm{kg}$ body weight. The animals were given intraperitoneally the lowest with dose of $250 \mathrm{mg} / \mathrm{kg}$ of the compounds at the first instance. If more than $50 \%$ mice die within $24 \mathrm{hrs}$, another group was chosen at a dose of $200 \mathrm{mg} / \mathrm{kg}$. If no death was observed, increasing dose up to limit dose of $2,000 \mathrm{mg} / \mathrm{kg}$ was injected to the mice. If more than $50 \%$ death was observed in limit test, the dose was then reduced to $800 \mathrm{mg} / \mathrm{kg}$. Acute half lethal dose $\left(\mathrm{LD}_{50}\right)$ was determined after observing toxic reaction for three days.

\section{Anti-inflammatory effect of TFC on cytokines levels}

Wistar rats (weighing $225 \pm 25 \mathrm{~g}$ ) were used in the study. This study was performed in accordance with the Guide for the Care and Use of Laboratory Animals. The study was approved by the ethics committee of Chinese Academy of Sciences, and all procedures complied with the guidance set out in the Guidelines for Caring for Experimental Animals published by the Ministry of Science and Technology of the People's Republic of China. Care was taken to minimize discomfort, distress, and pain to the animals. Forty healthy female adult rats were randomly divided in four groups. The TFC were presolubilized in mixture of DMSO, ethanol and polysorbate-80. This mixture was subsequently filled up with physiological saline to final concentrations of $4 \%$ DMSO,
$10 \%$ ethanol and $20 \%$ polysorbate-80. Intraperitoneal doses of 10, 20 and $30 \mathrm{mg} / \mathrm{kg}$ body weight were applied in a volume of $2 \mathrm{ml} / \mathrm{kg} 1 \mathrm{~h}$ before the injection of carrageenan. Diclofenac sodium $(1.7 \mathrm{mg} / \mathrm{kg})$ was used as a standard. Inflammatory response was induced by a single intrapleural injection of 0.1 mLof sterile saline solution $(\mathrm{NaCl}, 0.95 \%)$ plus carrageenan $(\mathrm{Cg}, 1 \%)$. Ten healthy rats treated only with intrapleural injection (i.p.) of sterile saline solution ( $\mathrm{NaCl}$ 0.95\%) used as control group. Six hours after the injection of carrageenan, blood samples were drawn from orbital vein from all the groups and serum was separated for biochemical estimations.

The level of TNF- $\alpha$, IL-1 $\beta$, VEGF- $\alpha$, and IL-17 in the rat blood samples were measured as previously described by Cai et al. [11]. Briefly, protein was extracted from the blood samples and the concentration was adjusted to $4 \mathrm{mg} / \mathrm{ml}$. The concentration of TNF- $\alpha$, IL- $1 \beta$, VEGF- $\alpha$, and IL-17 were then determined using a commercial ELISA kit (Shanghai Jinma Biological Technology, Inc., China) following the manufacture's instruction.

\section{Measurement of total antioxidant status}

The total antioxidant status (TAOS) of serum was determined as previously described by Laight et al. [12]. The increase of absorbance at $405 \mathrm{~nm}$ was measured by a microplate reader (Shanghai Xunda Medical Technology, Inc., China).

\section{Peripheral antinociceptive effect of TFC in animal model} Kunming outbred mice weighing 20-22 g, were purchased from the Experimental Animal Center, Shandong University. The mice were maintained at room temperature under alternating natural light/dark photoperiod, and had access to standard laboratory food and fresh water ad libitum.

Writhing test is used for the evaluation of peripheral analgesic activity. Mice were treated (intraperitoneal) with TFC of 10,20 and $30 \mathrm{mg} / \mathrm{kg}$ body weight $60 \mathrm{~min}$ before receiving a $0.6 \%$ acetic acid injection $(10 \mathrm{~mL} / \mathrm{kg}$, i.p.). The number of contractions or writhings, determined by abdominal muscle contractions and hind paw extension was recorded for $20 \mathrm{~min}$, starting $10 \mathrm{~min}$ after the administration of acetic acid. Diclofenac sodium $(1.7 \mathrm{mg} / \mathrm{kg})$ was used as standard.

Table 1 Effect of TFC on the Protein Levels of TNF- $\alpha$, IL-1 $\beta$, VEGF- $\alpha$, and IL-17

\begin{tabular}{lllll}
\hline Different groups & TNF- $\mathbf{a}(\mathbf{p g} / \mathbf{m L})$ & IL-1 $\boldsymbol{\beta}(\mathbf{p g} / \mathbf{m L})$ & VEGF- $\mathbf{a}(\mathbf{p g} / \mathbf{m L})$ & IL-17(pg/mL) \\
\hline Saline group & $3021.0 \pm 388.4$ & $1066.6 \pm 148.8$ & $1212.2 \pm 117.7$ & $867.1 \pm 58.4$ \\
Dic. group & $1620.6 \pm 118.0^{* *}$ & $676.7 \pm 64.0^{* *}$ & $675.5 \pm 22.5^{* *}$ & $91.5 \pm 6.5^{* * *}$ \\
TFC 10 group & $2718.7 \pm 370.2$ & $1084.0 \pm 84.3$ & $1090.0 \pm 44.1$ & $771.7 \pm 75.7$ \\
TFC 20 group & $2013.4 \pm 184.7$ & $866.7 \pm 70.3$ & $1054.4 \pm 44.5$ & $671.1 \pm 35.5$ \\
TFC 30 group & $1260.4 \pm 195.5^{* *}$ & $777.7 \pm 66.3^{*}$ & $648.0 \pm 20.2^{* *}$ & $93.5 \pm 9.5^{* * *}$ \\
\hline
\end{tabular}

Values are shown as means \pm SEM. ${ }^{*} p<0.05$ vs. Saline group, ${ }^{* *} p<0.01$ vs. Saline group, ${ }^{* * *} p<0.001$ vs. Saline group. 


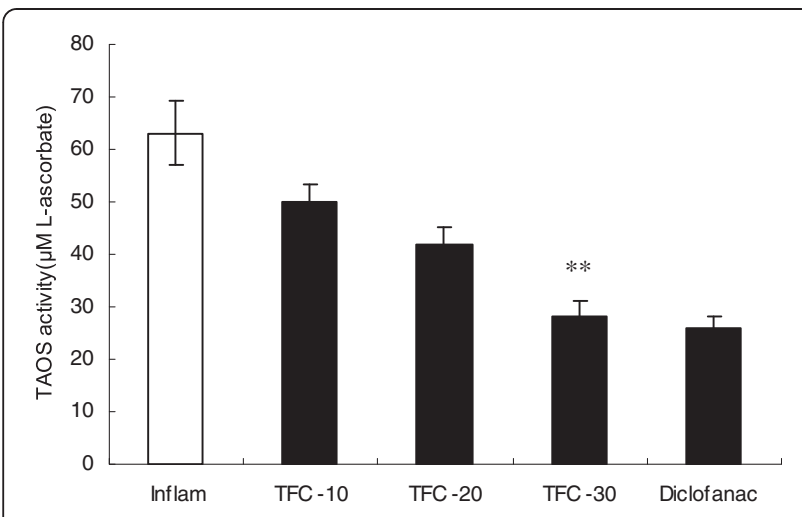

Figure 1 Effect of TFC on total antioxidant Activity. Values are shown as means \pm SEM. ${ }^{*} p<0.05$ vs. Saline group, ${ }^{* *} p<0.01$ vs. Saline group.

\section{Central antinociceptive effect of TFC in animal model}

The hot-plate test is commonly used to assess narcotic analgesics or other centrally acting drugs [13,14]. In this test, mice were pre-selected according to their reactions to a thermal stimulus (jumping or licking of hind limbs when placed on a hot plate at $55^{\circ} \mathrm{C}$ ). Latency times were recorded immediately before and 30, 60 and 90 min after drug administration (intrapleural injection with TFC of 10, 20and $30 \mathrm{mg} / \mathrm{kg}$ body weight, diclofanac sodium $1.7 \mathrm{mg} / \mathrm{kg}$ and sterile saline), up to a maximum time of $40 \mathrm{~s}$ to avoid paw lesions [15].

\section{Anti-hyperalgesia effect of TFC in animal model}

Mice received a single intraplantar injection of $100 \mu \mathrm{l}$ of $1 \mathrm{mg} / \mathrm{ml}$ dose of heat-killed and dried Mycobacterium tuberculosis in a mixture of paraffin oil and mannide monoleate. The tactile hyperalgesia was tested as tactile withdrawal threshold before and at 15, 30 and 60 min after drug administration.

\section{Statistical analysis}

The data were expressed as mean \pm S.E.M. and results were analyzed by ANOVA followed by Dunnett's $t$ test. $\mathrm{P}<0.05$ was considered significant.

Table 2 Peripheral antinociceptive effect of TFC in mice subjected to the writhing test

\begin{tabular}{lcc}
\hline Different groups & $\begin{array}{c}\text { Number of contraction } \\
(\mathbf{2 0} \text { } \mathbf{~ i n})\end{array}$ & $\begin{array}{c}\text { Inhibition } \\
\mathbf{( \% )}\end{array}$ \\
\hline Saline group & $25.1 \pm 2.2$ & - \\
Dic. group & $5.8 \pm 1.9$ & $76.9 \%$ \\
TFC 10 group & $15.0 \pm 2.1^{*}$ & $40.2 \%$ \\
TFC 20 group & $7.6 \pm 1.6^{* *}$ & $69.7 \%$ \\
TFC 30 group & $5.8 \pm 1.2^{* *}$ & $76.9 \%$
\end{tabular}

Values are shown as means \pm SEM. ${ }^{*} p<0.05$ vs. Distilled water group, ${ }^{* *} p$ $<0.01$ vs. Distilled water group $(n=10)$.
Table 3 Effect of TFC in mice subjected to the hot-plate test. $(\mathrm{N}=10)$

\begin{tabular}{lllll}
\hline Groups & \multicolumn{4}{c}{ Reaction time to the thermal stimulus (s) } \\
\cline { 2 - 5 } & $\mathbf{0} \mathbf{~} \mathbf{m i n}$ & $\mathbf{3 0} \mathbf{~} \mathbf{i n}$ & $\mathbf{6 0} \mathbf{~} \mathbf{i n}$ & $\mathbf{9 0} \mathbf{~}$ in \\
\hline Saline group & $10.9 \pm 0.6$ & $9.6 \pm 0.9$ & $8.3 \pm 0.80$ & $9.5 \pm 0.6$ \\
Dic. group & $9.9 \pm 0.8$ & $13.0 \pm 1.1^{*}$ & $16.3 \pm 0.6^{* *}$ & $16.8 \pm 1.5^{* *}$ \\
TFC 10 group & $11.9 \pm 1.5$ & $11.4 \pm 1.5$ & $8.8 \pm 1.2$ & $11.4 \pm 1.3$ \\
TFC 20 group & $10.9 \pm 2.2$ & $11.5 \pm 1.2$ & $9.8 \pm 1.1$ & $10.6 \pm 1.3$ \\
TFC 30 group & $13.9 \pm 1.1$ & $11.2 \pm 0.9$ & $11.4 \pm 1.7$ & $12.5 \pm 2.9$ \\
\hline
\end{tabular}

Values are shown as means \pm SD.

${ }^{*} p<0.05$ vs. control group, ${ }^{* *} p<0.01$ vs. control group.

\section{Results and discussion}

The present study demonstrates, for the first time, that the anti-inflammatory and analgesic effects of TFC. Carrageenan-induced inflammation in rats is a wellcharacterized experimental model of acute inflammation that permits the quantification and correlation of cellular migration with changes in other inflammatory parameters [16]. Diclofenac is a nonsteroidal anti-inflammatory drug used to treat pain andinflammation associated with arthritis. It was used as a standard. The inflammatory response involves a complex intercellular signal promoting cytokine release. Activated inflammatory cells synthesize and secrete proinflammatory cytokines such as TNF- $\alpha$, IL-1 $\beta$, VEGF- $\alpha$, and IL-17 [17-19]. The suppression of these proinflammatory mediators has been found to reduce the severity of the inflammatory reaction [20]. Some work has been done on the effects of the mushroom on cytokines and nuclear factor kappa B (NF-kB) levels [21-25]. The present study was undertaken to determine the effect of TFC on protein levels of TNF- $\alpha$, IL-1 $\beta$, VEGF- $\alpha$, and IL-17 during the inflammatory process induced by carrageenan.

Treatment with TFC $(30 \mathrm{~m} / \mathrm{kg})$ significantly reduced the levels of TNF- $\alpha$ by $58.3 \%$ (P $<0.01$ ), IL- $1 \beta$ by $27 \%$ $(\mathrm{P}<0.05)$,VEG $\mathrm{F}-\alpha$ by $46.5 \%(\mathrm{P}<0.01)$ and $\mathrm{IL}-17$ by $89.2 \%$ ( $\mathrm{P}<0.001$ ), respectively (Table 1 ). Results of this study clearly indicate the anti-inflammatory activity of the TFC in acute inflammatory conditions. It could effectively inhibit the leukocyte migration promoted by carrageenan in rat.

$\mathrm{O}_{2}^{-}$has been associated with tissue damage and loss of function during inflammatory episodes [26]. The total antioxidant status (TAOS) is an indication of $\mathrm{O}_{2}{ }^{-}$and other oxidant species. We measured TAOS activity as an indirect indication of the formation of $\mathrm{O}_{2}^{-}$and other oxidant species. The TFC $(10 \mathrm{~m} / \mathrm{kg})$ groups had the lower level of TAOS activity in comparison to the saline group $(\mathrm{P}<0.01)$ (Figure 1). It is consistent with the previous report on the antioxidant properties of Coprinus Comatus $[27,28] . \mathrm{O}_{2}{ }^{-}$is produced by polymorphonuclear leukocytes and macrophages from the enzyme activity of NADPH oxidase and 


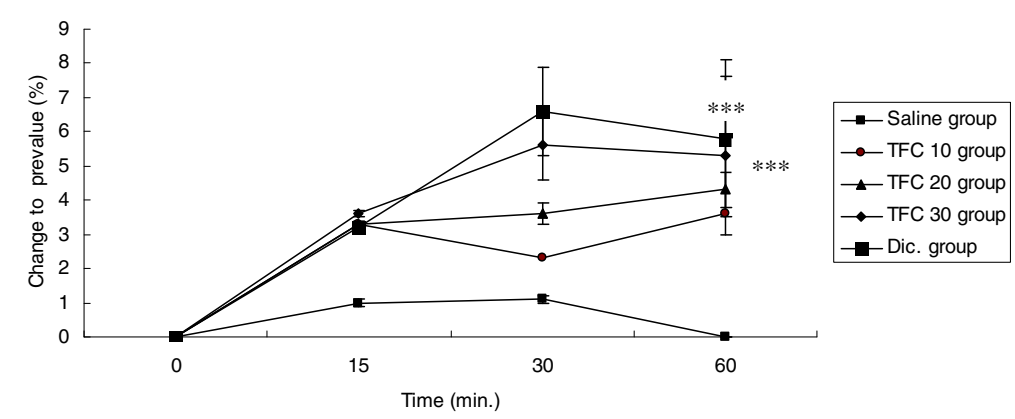

Figure 2 Effect of TFC on anti-hyperalgesia. Values are shown as means \pm SEM. ${ }^{* * *} p<0.0001$ vs. Saline group.

xanthine oxidase at inflammatory sites. We hypothesized that TFC produce anti-inflammatory effect through decreasing the levels of TAOS activities.

The report that no decrease in oedema induced by formalin injection was observed following treatment with C. comatus also showed that C. comatus had a peripheral antinociceptive and anti-inflammatory effect [29]. In the writhing test, TFC inhibited the acetic acid-induced abdominal constrictions in a dose-dependent manner $(40.2 \%, 69.7 \%$, and $76.9 \%)$ (Table 2). The acetic acidinduced writhing reaction in mice has been used as a screening tool for the assessment of analgesic or antiinflammatory properties of new agents [30]. The constrictions induced by acetic acid in mice result from an acute inflammatory reaction related to the increase in the peritoneal fluid levels of $\mathrm{PGE}_{2}$ and $\mathrm{PGF}_{2} \alpha$ [31]. The fact that TFC was able to inhibit constrictions showed that TFC has a peripheral antinociceptive effect.

On the contrary, the result of the hot-plate test did not show that TFC has a central antinociceptive effect. The hot-plate test is commonly used to assess narcotic analgesics or other centrally acting drugs $[13,14]$. The hot-plate test was performed for the assessment of the central antinociceptive effect of TFC in this study. Results showed that TFC inhibited the reaction time to thermal stimuli at 30, 60, and 90 min compared to controls. However, it was not significant (Table 3). The mechanism of TFC does not exert central antinociceptive effect could be explained that it has poor permeability across the blood brain barrier (BBB). BBB is an active interface between the circulation and the central nervous system (CNS) which restricts the free movement of different substances between the two compartments and plays a crucial role in the maintenance of the homeostasis of the CNS [32].

Complete Freund's adjuvant (CFA) -induced hyperalgesia is frequently used as an animal model to study chronic inflammatory pain. The CFA-induced inflammation is accompanied by a tactile hyperalgesia (HA), which is robust over several days [33]. TFC reduced dosedependently the CFA-induced tactile hyperalgesia
(Figure 2). It is likely that the antihyperalgesic effect of CFA was due to a genuine anti-inflammatory effect.

As per the OECD Guidelines-423, $\mathrm{LD}_{50}$ was calculated for TFC. When there is no information of TFC on toxicity, it is recommended to use the starting dose of $250 \mathrm{mg} / \mathrm{kg}$ body weight. This involves the estimation of the median lethal dose $\left(\mathrm{LD}_{50}\right)$, which is the dose that will kill $50 \%$ of the animal population within 72 hours post treatment with the test substance. After intraperitoneal injection, most mice in the $400 \mathrm{mg} / \mathrm{kg}$ group were quiet and inactive. Mice died approximately $7 \mathrm{hr}$ after injection. The majority of mice in the $400 \mathrm{mg} / \mathrm{kg}$ dose group (5 mice) died within $72 \mathrm{hr}$ following the injection. The $\mathrm{LD}_{50}$ was determined to be $400 \mathrm{mg} / \mathrm{kg}$.

\section{Conclusion}

In conclusion, TFC showed anti-inflammatory, antioxidant, peripheral antinociceptive and antihyperalgesic activity in various models of inflammatory pain. The data suggest that TFC may be a viable treatment option for inflammatory pain.

\section{Competing interests}

The authors declare that they have no competing interests.

\section{Authors' contributions}

J-YG and J-LS were involved in the design of this study and performed laboratory analyses and statistics. JR and C-CH drafted the manuscript along with the other authors. All authors read and approved the final manuscript.

\section{Acknowledgement}

This project was supported by the Key New Drugs Innovation project from Ministry of Science and Technology (2009ZX09103-381, 2009ZX09502-017, 2010ZX09102-201-018), the project from Key Laboratory of Mental Health, Chinese Academy of Sciences, project of Shandong Province Higher Educational Science and Technology Program (J08LH62), NNSF grant (30800301, 31170992) and the Knowledge Innovation Program of the Chinese Academy of Sciences (KSCX2-YW-R-254, KSCX2-EW-Q-18 and KSCX2EW-J-8).

\section{Author details}

${ }^{1}$ Department of Psychology, Zhejiang Normal University, Jinhua 321004, P. R. China. ${ }^{2}$ School of Pharmacy, Beijing University of Chinese Medicine, Beijing 100102, P. R. China. ${ }^{3}$ School of Pharmacy, Shandong University of Traditional Chinese Medicine, Jinan 250355, P. R. China. ${ }^{4}$ School of Basic Medical Sciences, Beijing University of Chinese Medicine, Beijing 100029, P. R. China. ${ }^{5}$ Key Laboratory of Mental Health, Institute of Psychology, Chinese Academy of Sciences, Beijing 100101, P. R. China. 
Received: 05 September 2011 Accepted: 24 April 2012

Published: 24 April 2012

\section{References}

1. Demirbas A: Heavy metal bioaccumulation by mushrooms from artificially fortified soils. Food Chem 2001, 74:293-301.

2. Cui M, Zhang H, An L: Tumor growth Inhibition by polysaccharide from Coprinus comatus. World Chin J Digestol 2002, 10:287-290.

3. Xing F, Wang H, Han C, Wang Y: Study on the immunocompetence of polysaccharides from the Coprinus comatus. J Food Sci (In Chinese) 2003, 24:139-141.

4. Gu Y, Ju Y: Food and officinal mushroom-Coprinus comatus. Vegetable (In Chinese) 1996, 13:10.

5. Stadler M, Hellwig V, Mayer-Bartschmid A, Denzer D, Wiese B, Burkhardt N: Novel Analgesic Triglycerides from Cultures of Agaricus macrosporus and Other Basidiomycetes as Selective Inhibitors of Neurolysin. J Antibiot (Tokyo) 2005, 58:775-786.

6. Han C: A comparison of antinociceptive activity of mycelial extract from three species of fungi of basidiomycetes. Open Complement Med J 2009, 1:73-77.

7. LV Y, Han L, Yuan C, Guo J: Comparison of hypoglycemic activity of trace elements absorbed in fermented mushroom of coprinus comatus. Biol Trace Elem Res 2009, 131:177-185.

8. $\mathrm{Xu} \mathrm{Q}$, Guo J: Activity and toxicity of $\mathrm{Cr}$ (III)-enriched Grifola frondosa in insulin-resistant mice. Biol Trace Elem Res 2009, 131:271-277.

9. Guo JY, Han CC, Liu YM: A contemporary treatment approach to both diabetes and depression by cordyceps sinensis, rich in Vanadium. Evid Based Complement Alternat Med 2010, 7:387-389.

10. Han CC: Antinociceptive activity of agaricoglycerides extracted from mycelium of Ling Zhi or Reishi medicinal mushroom, Ganoderma lucidum (W. Curt.: Fr.) P. Karst. (Aphyllophoromycetideae). Int J Med Mushrooms 2010, 12:273-278

11. Cai Z, Pang Y, Lin S, Rhodes PG: Differential roles of tumor necrosis factoralpha and interleukin-1 beta in lipopolysaccharide-induced brain injury in the neonatal rat. Brain Res 2003, 975:37-47.

12. Laight DW, Gunnarsson PT, Kaw AV, Carrier MJ: Physiological microassay of plasma total antioxidant status in a model of endothelial dysfunction in the rat following experimental oxidant stress in vivo. Environ Toxicol Pharmacol 1999, 7:27-31

13. Guo JY, Wang JY, Luo F: Dissection of placebo analgesia in mice: the conditions for activation of opioid and non-opioid systems. $J$ Psychopharmacol 2010, 24:1561-1567.

14. Guo JY, Yuan XY, Sui F, Zhang WC, Wang JY, Luo F, Luo J: Placebo analgesia affects the behavioral despair tests and hormonal secretions in mice. Psychopharmacology 2011, 217:83-90.

15. Woolfe G, MacDonald AD: The evaluation of the analgesic action of pethidine hydrochloride (demerol). J Pharmacol Exp Ther 1944, 80:300-307.

16. Moore AR: Pleural models of inflammation: immune and nonimmune. Methods Mol Biol 2003, 225:123-128.

17. Calcagni E, Elenkov I: Stress system activity, innate and T helper cytokines, and susceptibility to immune-related diseases. Ann N Y Acad Sci 2006, 1069:62-76.

18. Schiller M, Metze D, Luger TA, Grabbe S, Gunzer M: Immune response modiiers-mode of action. Exp Dermatol 2006, 15:331-341.

19. Annunziato F, Cosmi L, Liotta F, Maggi E, Romagnani S: The phenotype of human Th17 cells and their precursors, the cytokines that mediate their differentiation and the role of Th17 cells in inlammation. Int Immunol 2008, 20:1361-1368.

20. Stow JL, Ching Low P, Offenhäuser C, Sangermani D: Cytokine secretion in macrophages and other cells: pathways and mediators. Immunobiology 2009, 214:601-614.

21. Jeurink PV, Noguera CL, Savelkoul HF, Wichers HJ: Immunomodulatory capacity of fungal proteins on the cytokine production of human peripheral blood mononuclear cells. Int Immunopharmacol 2008, 8:11241133.

22. Asatiani MD, Wasser SP, Nevo E, Ruimi N, Mahajna J, Reznick AZ: The Shaggy Inc Cap medicinal mushroom, Coprinus comatus (O.F.Mull.: Fr.) Pers.(Agaricomycetideae) substances interfere with $\mathrm{H} 2 \mathrm{O} 2$ induction of the NF-kappaB pathway through inhibition of Ikappaalpha phosphorylation in MCF7 breast cancer cells. Int J Med Mushrooms 2011 13:19-25.
23. Beattie KD, Ulrich R, Grice ID, Uddin SJ, Blake TB, Wood KA, Steele J, Iu F, May TW, Tiralongo E: Ethanolic and aqueous extracts derived from Australian fungi inhibit cancer cell growth in vitro. Mycologia 2011, 103:458-465.

24. Gu YH, Leonard J: In vitro effects on proliferation, apoptosis and colonyinhibition in ER-dependent and ER-independent human breast cancer cells by selected mushroom species. Oncol Rep 2006, 15:417-423.

25. Zaidman BZ, Wasser SP, Nevo E, Mahajna J: Coprinus comatus andGanoderma lucidum interfere with androgen receptor function in LNCaP prostate cancer cells. Mol Boil Rep 2008, 35:107-117.

26. Vega VL, Maldonado M, Mardones L, Manríquez V, Vivaldi E, Roa J, Ward PH: Inhibition of nitric oxide synthesis aggravates hepatic oxidative stress and enhances superoxide dismutase inactivation in rats subjected to tourniquet shock. Shock 1998, 9:320-328.

27. Li B, Lu F, Suo X, Nan H: Antioxidant properties of cap and stipe fromCoprinus comatus. Molecules 2010, 15:1473-1486.

28. Popovic M, Vukmirovic S, Stilinovic N, Capo I, Jakovljevic V: Anti-oxidative activity of an aqueous suspension of commercial preparation of the mushroom Coprinus comatus. Molecules 2010, 15:4564-4571.

29. Sabo A, Stilinovic N, Vukmirovic S, Bukumiric Z, Capo I, Jakovljevic V: Pharmacodynamic action of a commercial preparation of the mushroom Coprinus comatus in rats. Phytother Res 2010, 24:1532-1537.

30. Collier HOJ, Dinneen JC, Johnson CA, Schneider C: The abdominal constriction response and its suppression by analgesic drugs in the mouse. Br J Pharmacol Chemother 1968, 32:295-310.

31. Deraedt $R$, Jouquey $S$, Delevalée $F$, Flahaut $M$ : Release of prostaglandins- $E$ and prostaglandins- $F$ in an algogenic reaction and its inhibition. Eur $J$ Pharmacol 1980, 61:17-24.

32. DiNunzio JC, Williams RO: CNS disorders-current treatment options and the prospects for advanced therapies. Drug Dev Ind Pharm 2008, 34:11411167.

33. Ma QP, Woolf CJ: Progressive tactile hypersensitivity: an inflammation induced incremental increase in the excitability of the spinal cord. Pain 1996, 67:97-106

doi:10.1186/1472-6882-12-52

Cite this article as: Ren et al: Isolation and biological activity of triglycerides of the fermented mushroom of Coprinus comatus. BMC Complementary and Alternative Medicine 2012 12:52.

\section{Submit your next manuscript to BioMed Central and take full advantage of:}

- Convenient online submission

- Thorough peer review

- No space constraints or color figure charges

- Immediate publication on acceptance

- Inclusion in PubMed, CAS, Scopus and Google Scholar

- Research which is freely available for redistribution 